\title{
Details of the analytic hierarchy process technique for the evaluation of health insurance companies
}

\author{
Dewey Wollmann ${ }^{\mathrm{a}}$, Maria Teresinha Arns Steiner ${ }^{\mathrm{b} *}$, Guilherme Ernani Vieirac, \\ Patrícia Arns Steiner ${ }^{\mathrm{d}}$ \\ adewey.wollmann@pucpr.br, PUCPR, Brasil \\ b*maria.steiner@pucpr.br, PUCPR, Brasil \\ 'gui.vieira@pucpr.br, PUCPR, Brasil \\ dpatriciaasteiner@gmail.com, UFPR, Brasil
}

\begin{abstract}
One of the most important features to be considered by health service providers when developing and promoting their products (or services) is the consumers' perception of their products' (services') attributes. The purpose of this study is to define the hierarchy for the attributes of services developed by major health plan operators in the city of Curitiba (PR) as perceived their consumers. The classical analytical hierarchy process (AHP) technique, a multicriteria tool for decision analysis and planning, was used to analyze seven companies and six attributes of each of them. The results show that the most meaningful attribute for health service consumers is the "price" and that companies can be separated into the following groups: HP1 and HP2 (Health Plans 1 and 2, with approximately 23\% and 19\% of consumers preferring each one) and HP3, HP4, HP5, HP6 and HP7 (with approximately 10\% of consumers preferring each). Based on the results for each attribute analyzed, the conditions exist for the companies to redefine their structures, processes, prices, and service providers to reach their target customers.
\end{abstract}

Keywords

$A H P$ process. Health service operators' attributes. Consumers' perceptions.

\section{Introduction}

The knowledge of a company about how different people view and value its products is critical in determining its goals and marketing strategies. The image, as a set of mental representations, both affective and cognitive, that an individual (or group of individuals) associates with a brand or company is closely linked to the identity of that brand or company.

It is important to understand these two concepts, since with the one (identity) the definition of personality is expressed, and with the other (image), the perception of that personality. Personality, according to Aaker (1996), is a set of human characteristics associated with a particular brand. The brand's personality should create a strong and, consequently, lasting relationship with its customers because, just as human personalities affect relationships between people, the personality of a brand can build the basis of the relationship between the client and itself. Thus, image and identity are intrinsically connected (AAKER, 1996).

Consequently, it is interesting for every company to know how its image is perceived by potential consumers, and from this knowledge, to redesign its products and services, if necessary. One technique that has proven quite effective in several studies, among which the image of companies before customers, is the Analytic Hierarchy Process (AHP) technique.

The objective of this work is to use AHP to study the image of seven leading health insurance providers in the city of Curitiba and its metropolitan area. Companies were analyzed from the perspective of six attributes considered by users as the most significant: location (point of service), effectiveness (the work of doctors, clinics and hospitals), responsiveness and 
friendliness (in the care of patients and their families), speed (in clearing payments for consultations, tests, hospitalizations and surgeries), price and coverage of the accredited providers (physicians, clinics and hospitals).

The results of the study show: 1) how the attributes are ranked by consumers; (2) the consumer perception of these companies' images in relation to the attributes and (3) the global consumer perception of these companies' images.

This paper is organized as follows: section 2 presents some work related to this subject, section 3 presents an introduction to the multiple-attribute methods; section 4 presents the AHP process in general. Data collection (six attributes of seven health insurance companies in the city of Curitiba and its metropolitan area), on the issue addressed here is presented in section 5. Section 6 presents the results and a discussion about them and, finally, section 7 presents the conclusions of this work.

\section{Related works}

A company, in order to market a product or service, must design an identity or personality targeting an audience (potential customers). This is done by defining the marketing mix (target audience, positioning, product, promotion, place, employees, suppliers, aftermarket and legal protection) that enables the creation of values, thus granting the brand the uniqueness required to compete in the market (AAKER, 1996). Target marketing, for instance, analyses and evaluates a product or a service and creates an image for the company. And it is this image that determined the foundation of the relationship between the company and its target audience (AAKER, 1996).

Some works related to the subject focused here, using multicriteria decision-making method to analyze the image of companies as perceived by customers or for other purposes, are briefly mentioned below.

Valois and Almeida (2009) introduced a decisionmaking model to structure the dilemma between outsourcing and carrying out the activities of a company in-house. The decision on what activities should be outsourced was analyzed on the basis of quality, costs, reliability and others. The model proposed was founded on the multiattribute theory, using the SMARTS (Simple Multiattribute Rating Technique using Swings) technique.

Branco, Ribeiro and Tinoco (2010) carried out research in order to determine the quality attributes perceived and the construction of a model of association of customer satisfaction determinants in hotel services. The main contribution of this work was to propose a model to determine the power of the relationship between customer satisfaction determinants and the hierarchy of the attributes with the greatest influence on the perceived quality of hotel services.

Some other papers specifically employing the AHP technique are also worth mentioning. Blanco (1996), studied the image of the main banks in Spain in terms of some attributes. In that study, the author presented the hierarchy of preferences of different users, according to various attributes considered essential to the Spanish banking system. Costa and Moll (1999), employed the AHP technique to study the process of selecting which sugarcane varieties should be grown by an ethanol-producing company, so as to maximize their results.

Munhoz and Castilho (2009), developed a methodology to identify and select the best alternative for the acquisition of an information system, using the AHP technique. Steiner, Braga and Steiner (2010), also using AHP concepts, studied the solid waste management systems of shopping malls in the city of Curitiba, PR, identifying the main management practices in each one. Ishizaka (2012), presented a method with clusters and picots, in order to reduce the judgements in the comparison matrices in AHP. Cruz Junior and Carvalho (2003), used the AHP in order to verify the consumers' satisfaction in an ecological hotel's services sector.

Vaidyaa and Kumarb (2006), did extensive research to identify how various researchers have used the AHP technique. They analyzed 150 scientific articles published in the most prestigious international journals, which dealt with issues related to products and services such as: selection (32 articles), evaluation (26 articles), cost-benefit analysis (7 articles), resource allocation (10 articles), planning and development (18 articles), prioritization (20 articles), decision making (21 articles), forecasting (4 articles), medicine (5 articles) and AHP including QFD (Quality Function Deployment; 7 articles). Of these articles, 70 were written by Americans, 27 by Europeans, 50 by Asians and 3 by researchers from other countries. Thus, we have demonstrated the diversity of the applicability of AHP and how the technique is widespread in many countries.

Liberatore and Nydick (2008) reviewed the literature on the application of $A H P$ in health care services between 1988 and 2006. They analyzed 50 articles, classified in seven categories: diagnosis, patient participation, therapy/treatment, organ transplantation, project and technology evaluation and selection, human resource planning, and health care evaluation and policy. The largest number of articles was found in the project and technology evaluation and selection 
category (14). The AHP appears to be a promising support tool for shared decision making in the health care setting.

\section{Multiple-attribute methods}

Hwang and Yoon (1981) classified 17 typical Multiple Attribute Decision-Making or simply MADM using as distinguishing criteria the type and particularities of the information provided by decision-makers.

The same authors later established a modified taxonomy for 13 methods. There, the methods are initially categorized by the type of information received from decision-makers: (i) if no information is given, the dominance method is applicable; (ii) if information on the environment is either optimistic and pessimistic, the Maximin or Minimax method is applicable; (iii) if information on attributes is given, the methods are grouped in subcategories.

The information provided by decision-makers may follow a pattern of attribute importance (same importance coefficient for all attributes), and this characteristic is linked to conjunctive and disjunctive methods. However, the importance of the attributes may differ, and this goes back to the French and American methods.

The American methods are related to the Multiattribute Utility Theory, grounded on the hypothesis that in any decision-making problem there is a real value function on the set of alternatives, and this function aggregates the attributes and should be determined by the decision-maker. Thus, the theory assumes that the decision-maker is able to identify several discrete alternatives for evaluation and is also able to structure the criteria on the basis of which the alternatives will be hierarchically evaluated.

One of the methods most widely known and used in the world is perhaps AHP. This method is based on the hierarchical analysis concept, structuring the criteria in hierarchical levels, so as create homogeneity among same-level criteria, that is, the criteria should have the same importance, thus rendering their understanding and evaluation easier.

Other versions were built on the classical model in an attempt to overcome some deficiencies, such as the (i) Multiplicative AHP, proposed Lootsma (1990), introducing changes to the preference aggregation rule; (ii) Referenced $A H P$ proposed by Watson and Freeling (1982), introducing a proportionality constant as a result of the comparison between the relative criterion and alternative values; (iii) $A H P$ B-G, proposed by Belton and Gear (1985), using the highest preference value among the alternatives (identified after comparing the alternatives) in order to normalize the preferences in relation to all others.

The French methods are more flexible models, not necessarily assuming the comparison of the alternatives and not imposing a hierarchical criteria structure on decision-makers. The first authors of this school of thought were those of the ELECTRE (Elinúnation Et Choix Traduisant la Réalite) family, proposed by Roy (1986), the main characteristic of which is related to a new concept of preference model, intended to be a more realistic representation than the one employed by the Classical Decision-Making Theory. Some related works exploring the ELECTRE TRI technique can be cited: Costa et al. (2007), used this method to evaluate the costumers' satisfaction about services; Szajubok, Mota and Almeida (2006), used this technique in the civil construction materials management study; Miranda and Almeida (2003), in order to evaluate the postgraduate courses in Brazil, used this multicriteria technique.

Another, more recent family of French methods is called PROMETHEE (Preference Ranking Organization Method for Enrichment Evaluations) and was initially proposed by Brans, Mareshal and Vincke (1984). The PROMETHEE methods use binary comparisons of the alternatives, assessing their performance criteria by criteria, so as to arrange the alternatives in order of priority. Furthermore, they employ the pseudo criteria concept, and the possibility of associating indifference and strict preference limits to the pseudo-criteria. Therefore, according to the performance differences existing between alternatives, decision-makers may vary the degree of preference (credibility index) of an alternative over another.

Considering the characteristics of this study, mainly in what concerns the interviewees (the decisionmakers), the classical $A H P$ method was chosen. The idea was to minimize the problems pointed out by Bond, Carlson and Keeney (2008) with decisionmakers determining the criteria and ranking them in their decision-making processes. The reason for that is, as already explained, that $A H P$ structures criteria in hierarchical levels, making it easier for decisionmakers to understand them.

\section{The ahp technique}

Multicriteria programming with the AHP process is structured for decision-making in complex environments, in which several variables or criteria for prioritizing and selecting alternatives are considered.

The AHP was developed in the 80's by Thomas $\mathrm{L}$. Today it is applied to decision-making in various complex scenarios in which people work together 
to make decisions and where human perceptions, judgments and consequences have long-term repercussions (BHUSHAN; RAY, 2004).

The AHP process begins by breaking the problem down into a hierarchy of criteria or attributes that are more easily analyzed and compared independently, as depicted in Figure 1. Once this logical hierarchy is constructed, the next step in AHP is to systematically evaluate all alternatives by comparing two at a time, based on each criterion or attribute. This comparison can use hard data and human judgments of the alternatives as a source of information (SAATY, 1980).

AHP transforms often empirical comparisons into numerical values to be processed. The weight of each factor allows the evaluation of each of the elements within the defined hierarchy. This ability to transform empirical data into numerical values is the main difference of AHP over other techniques.

The comparison between two elements using AHP can be achieved in different ways (TRIANTAPHYLLOU; MANN, 1995) However, the scale of relative importance between two alternatives proposed by Saaty (2005) is the most widely used. By assigning values ranging from "1" through "9", the scale determines the relative importance of alternative $i$ over alternative $\mathrm{j}$ and, conversely, alternative $\mathrm{j}$ over alternative ii, as shown in Table 1.

The use of this scale for the assessment criteria and/or attributes generates a matrix with numerical values as presented Table 2 .

The same procedure is used for peer review of alternatives from the perspective of each of the criteria and/or attributes. Thus, for example, for attribute 1 , alternatives will be analyzed according to the matrix shown in Table 3.

These evaluations and their weight assignments must be made by each of the $K$ people who are participating in the process of evaluating alternatives. Using the evaluation matrices of all $K$ people, a single set of matrices (attributes and alternatives of attributes) must be established representing the whole evaluation process.

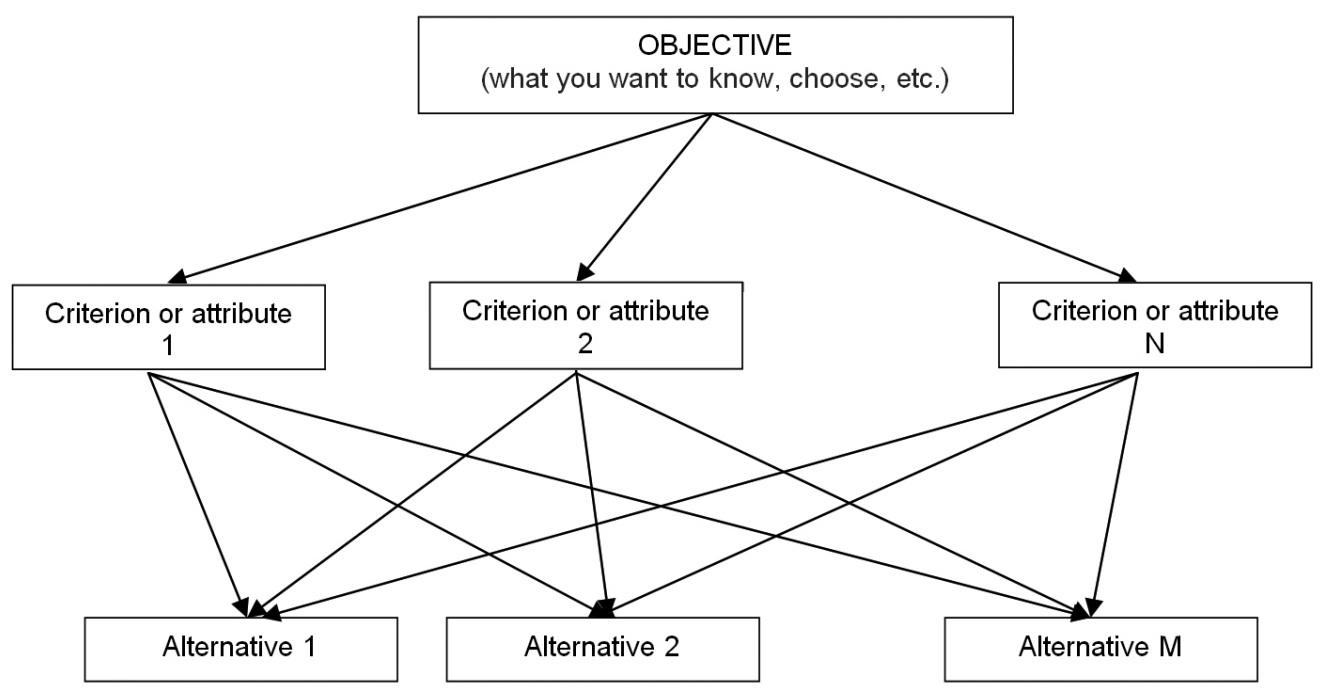

Figure 1. Comparisons performed with the AHP technique.

Table 1. Saaty's scale of relative importance (SAATY, 2005).

\begin{tabular}{lcc}
\multicolumn{1}{c}{ Scale } & $\begin{array}{c}\text { Numerical evaluation }\left(\mathrm{a}_{\mathrm{ij}}\right) \\
\text { (Alternative } \mathrm{i} \text { from } \mathrm{j} \text { ) }\end{array}$ & $\begin{array}{c}\text { Reciprocal }\left(1 / \mathrm{a}_{\mathrm{ij}} \text { ) }\right. \\
\text { (Alternative } \mathrm{i} \text { from } \mathrm{j} \text { ) }\end{array}$ \\
\hline Extremely preferred & 9 & $1 / 9$ \\
Between very strong and extremely & 8 & $1 / 8$ \\
Very strongly preferred & 7 & $1 / 7$ \\
Between strong and very strong & 6 & $1 / 6$ \\
Very strongly preferred & 5 & $1 / 5$ \\
Between moderate and strong & 4 & $1 / 4$ \\
Moderately preferred & 3 & $1 / 3$ \\
Between equal and moderate & 2 & $1 / 2$ \\
Very strongly preferred & 1 & 1 \\
\hline
\end{tabular}


According to studies by Aczél and Saaty (1983), the geometric mean of the values should be used, because thus the characteristics of the weights and their reciprocals, are maintained. In numerical terms, each element of the consolidated matrices $a_{\mathrm{ij}}{ }^{\mathrm{c}}$ is determined by Equation 1.

$a_{i j}^{c}=\sqrt[K]{\Pi_{1}^{K} a_{i j}^{k}}$

After obtaining the consolidated matrices, the values must be standardized as to the columns. This is represented in Tables 4 and 5.

where each matrix element is given by Equation 2 .

$$
a_{i j}^{c^{\prime}}=\frac{a_{i j}^{c}}{\sum_{1}^{J} a_{i j}^{c}}
$$

From the array of consolidated and standardized attributes, one can calculate the relative weights among the criteria and/or attributes. These weights are determined by calculating the arithmetic mean of the elements of their respective lines, as shown by Equation 3.

$p_{i}=\frac{\sum_{1}^{J} a_{i j}^{c}}{N}$

After determining the weights of each criterion and/or attribute, one may establish the hierarchy between them. This means obtaining the degree of importance that people "give" to each of the criteria and /or attributes.

Similarly, the same mathematical process is performed for each of the alternatives from the perspective of each attribute. The values of the weights $\left(p a_{i j}\right)$ mean classifying (ranking) the alternatives from the perspective of each attribute.

Finally, in order to obtain the final result of the analysis, the overall weight of each alternative is determined. For this, we calculate the weighted average of the weights of each alternative in terms of the various attributes, according to Equation 4.

Table 2. Example of assessment criteria and/or attribute matrix.

\begin{tabular}{|c|c|c|c|c|}
\hline ATTRIBUTES & Attribute 1 & Attribute 2 & ......... & Attribute $\mathrm{N}$ \\
\hline Attribute 1 & 1 & $1 / a_{21}$ & ......... & $1 / a_{\mathrm{N} 1}$ \\
\hline Attribute 2 & $a_{21}$ & 1 & & $1 / a_{\mathrm{N} 2}$ \\
\hline .......... & ......... & ......... & ......... & ......... \\
\hline Attribute N & $a_{\mathrm{N} 1}$ & $a_{\mathrm{N} 2}$ & ......... & 1 \\
\hline
\end{tabular}

Table 3. Example of an evaluation matrix for alternatives based on attribute 1.

\begin{tabular}{|c|c|c|c|c|}
\hline ALTERNATIVES & Alternative 1 & Alternative 2 & $\ldots \ldots .$. & Alternative M \\
\hline Alternative 1 & 1 & $1 / a_{21}$ & $\ldots \ldots .$. & $1 / a_{\mathrm{M} 1}$ \\
\hline Alternative 2 & $a_{21}$ & 1 & & $1 / a_{\mathrm{M} 2}$ \\
\hline ......... & ......... & .......... & ......... & ......... \\
\hline Alternative M & $a_{\mathrm{M} 1}$ & $a_{\mathrm{M} 2}$ & $\ldots \ldots \ldots$ & 1 \\
\hline
\end{tabular}

Table 4. Example of attribute standardized matrix.

\begin{tabular}{|c|c|c|c|c|}
\hline ATTRIBUTES & Attribute 1 & Attribute 2 & ......... & Attribute $\mathrm{N}$ \\
\hline Attribute 1 & $a_{11}{ }^{c}$ & $a_{12}{ }^{c^{\prime}}$ & $\ldots \ldots .$. & $a_{1 \mathrm{~N}}{ }^{c^{\prime}}$ \\
\hline Attribute 2 & $a_{21}{ }^{c^{\prime}}$ & $a_{22}{ }^{c^{\prime}}$ & & $a_{2 \mathrm{~N}}{ }^{c^{\prime}}$ \\
\hline ......... & ......... & .......... & .......... & ......... \\
\hline Attribute N & $a_{\mathrm{N} 1}{ }^{c^{\prime}}$ & $a_{\mathrm{N} 2}{ }^{c^{\prime}}$ & ......... & $a_{\mathrm{NN}}{ }^{\prime}$ \\
\hline
\end{tabular}

Table 5. Example of alternatives from the perspective of attribute 1 standardized matrix.

\begin{tabular}{|c|c|c|c|c|}
\hline ALTERNATIVES & Alternative 1 & Alternative 2 & .......... & Alternative M \\
\hline Alternative 1 & $a_{11}{ }^{c^{\prime}}$ & $a_{12}{ }^{c^{\prime}}$ & ............. & $a_{1 M}{ }^{c^{\prime}}$ \\
\hline Alternative 2 & $a_{21}{ }^{c^{\prime}}$ & $a_{22}{ }^{c^{\prime}}$ & & $a_{2 M}{ }^{c^{\prime}}$ \\
\hline .......... & .......... & .......... & .......... & .......... \\
\hline Alternativea M & $a_{\mathrm{M} 1}{ }^{{ }^{\prime}}$ & $a_{\mathrm{M} 2}{ }^{\mathrm{c}^{\prime}}$ & ......... & $a_{\mathrm{MM}}$ \\
\hline
\end{tabular}




$$
p g_{j}=\sum_{1}^{J}\left(p_{i}\right) \cdot\left(p a_{i j}\right)
$$

When the global weights are known, it is finally possible to rank the alternatives, starting with the highest value.

So, in summary, the $A H P$ process allows to: (1) Rank the criteria and/or attributes (sort $p_{\mathrm{j}}$ ); (2) Rank the alternatives from the perspective of each criteria and/or attribute (sort the $p a_{i j}$ ) and, finally, (3) Rank the alternatives from the perspective of all criteria and/or attributes simultaneously $\left(p g_{\mathrm{j}}\right)$.

\section{Obtaining data}

The objective of this work is to use $A H P$ to study the image of seven leading health insurance carriers in the city of Curitiba and its metropolitan area. Companies were analyzed from the perspective of six attributes listed below. As already mentioned, the results of this study will also point out: (1) how the attributes are ranked by consumers; (2) the consumer perception of these companies' images in relation to the attributes and (3) the global consumer perception of these companies' images.

\subsection{Key attributes of a health provider}

A key aspect to study the image of a company is the identification of attributes that characterizes it. In the case of companies operating health plans, the attributes of greater relevance to users are listed below.

Parasuraman, Berry and Zeithaml (1990) affirm that the quality of the services may be described on the basis of ten dimensions, namely: tangibles, reliability, responsiveness, competence, courtesy, credibility, security, accessibility, communication and understanding the customer. In order to measure the customer's perception of the service quality, those authors developed a tool called SERVQUAL, based on these ten dimensions. Those authors argue that to achieve high service quality a balance must be struck between customer expectations and experience, bringing them closer to one another. Thus, in order to increase customer satisfaction, the service provider must establish a connection between the quality of the internal processes and the customer's quality experience and satisfaction, which involves an important and complex translation process (GUSTAFSSON; JOHNSON, 1997).

Considering all that and with the help of experts in health care insurance operators, the most relevant attributes for users were determined as being:
$>$ Location of service points, since it directly impacts the logistics required to the displacement of users;

$>$ Effectiveness of doctors, clinics and hospitals, which is crucial for users when ill;

$>$ Responsiveness and kindness in caring for patients and families, related to the anxiety of users about solving their problems;

$>$ Speedy clearing of payment for consultations, tests, hospitalizations and surgeries, related to consumer rights;

$>$ Price, which might be considered the quantification of the service provided by companies;

$>$ Coverage of the network of accredited doctors, clinics and hospitals, which relates to the quality and effectiveness of the health-care staff and facilities.

\subsection{User survey of health plans}

The seven companies surveyed, hereinafter referred to as HP1, HP2, HP3, HP4, HP5, HP6 and HP7, area responsible for $95 \%$ of health insurance coverage in Curitiba and its metropolitan area. We interviewed 400 people in these regions, ranging from 18 to 65 years of age, customers of these seven health-care insurance providers. Interviewee selection was carried out by simple randomization, that is, it was quite "democratic", since users were not asked about their own health insurance providers, nor about their socio-economic status.

It must be pointed out that this procedure was chosen because the aim of this study was to assess the image of the health insurance providers in the city of Curitiba and therefore the perception of respondents who already have health insurance must be taken into in the sampling, as was done here. Therefore, companies may identify, on the basis of the results, their strengths and weaknesses as seen by the people of Curitiba, and design their strategies for this market accordingly.

Of the 400 interviews, 360 were considered valid; supervision took place by phone calls to interviewees $(10 \%)$ or personal supervision (17\%). The questions asked are listed further on.

Considering the sample characteristics and in order to ensure the consistency of the preference ranking matrices, the procedure adopted was the same employed by Silva (2007), who suggested that the poll should have a minimum number of peer judgment questions, and the other values be derived from those, thus preventing interviewees from expressing inconsistent judgments of values.

The poll included the following questions. 
$>$ Indicate, for each pair of attributes listed in Table 6, the most preferred (attribute ranking).

$>$ For each attribute on Table 7 , indicate the one you prefer (company ranking).

\section{Collection and discussion ofthe results}

The consolidated matrix which starts ranking health insurance user preferences in terms of the attributes listed in section 4.1 is presented in Table 8 .

The consistency of this matrix is ensured by the fact that the preferences in the columns corresponding to attributes effectiveness, responsiveness, speed, price and coverage were determined according to the values of the attribute "location". Thus, for example, "effectiveness" is 4.25 (position $(2,1)$ matrix) times more dominant than "location"; the "responsiveness" is 2.75 (position $(3,1)$ matrix) times more dominant than attribute "location". Thus, attribute "responsiveness" is 0.65 (position $(3,2)$ times more dominant than attribute "effectiveness" $(2,75$ / 4,25). In this same way, one can calculate all the values contained in Table 8. Standardizing the consolidated matrix of Table 8, we obtain Table 9.

The weights for each one of the companies' attributes are determined on the basis of the standardized matrix, employing the mean of the values of each line and, also, their respective percentages. These weights represent the importance that the health

Table 6 . Indicate the attributes by decision-maker preferences.

\begin{tabular}{|c|c|c|c|c|c|c|c|c|c|c|}
\hline & 9 & 7 & 5 & 3 & 1 & 3 & 5 & 7 & 9 & \\
\hline Location & & & & & & & & & & Effectiveness \\
\hline Location & & & & & & & & & & Speed \\
\hline$\ldots \ldots$. & & & & & & & & & & $\ldots . . .$. \\
\hline Location & & & & & & & & & & Coverage \\
\hline
\end{tabular}

Table 7. Indicate the company you prefer, in terms of each attribute.

\begin{tabular}{|c|c|c|c|c|c|c|c|c|c|c|}
\hline \multicolumn{11}{|c|}{ Location } \\
\hline & 9 & 7 & 5 & 3 & 1 & 3 & 5 & 7 & 9 & \\
\hline HP1 & & & & & & & & & & HP2 \\
\hline HP1 & & & & & & & & & & HP3 \\
\hline ......... & & & & & & & & & & ......... \\
\hline HP1 & & & & & & & & & & HP7 \\
\hline \multicolumn{11}{|c|}{ Effectiveness } \\
\hline & 9 & 7 & 5 & 3 & 1 & 3 & 5 & 7 & 9 & \\
\hline HP1 & & & & & & & & & & HP2 \\
\hline HP1 & & & & & & & & & & HP3 \\
\hline ........ & & & & & & & & & & ........ \\
\hline HP1 & & & & & & & & & & HP7 \\
\hline \multicolumn{11}{|c|}{ Coverage } \\
\hline & 9 & 7 & 5 & 3 & 1 & 3 & 5 & 7 & 9 & \\
\hline HP1 & & & & & & & & & & HP2 \\
\hline HP1 & & & & & & & & & & HP3 \\
\hline ......... & & & & & & & & & & ......... \\
\hline HP1 & & & & & & & & & & HP7 \\
\hline
\end{tabular}

Table 8. Consolidated Matrix of company attribute preferences.

\begin{tabular}{lcccccc}
\hline \multicolumn{1}{c}{ ATTRIBUTES } & Location & Effectiveness & Fast & Convenient & Price & Coverage \\
\hline Location & 1.00 & 0.24 & 0.36 & 0.17 & 0.12 & 0.27 \\
Effectiveness & 4.25 & 1.00 & 1.55 & 0.74 & 0.52 & 1.13 \\
Speed & 2.75 & 0.65 & 1.00 & 0.48 & 0.34 & 0.73 \\
Convenient & 5.75 & 1.35 & 2.09 & 1.00 & 0.71 & 1.53 \\
Price & 8.15 & 1.92 & 2.96 & 1.42 & 1.00 & 2.17 \\
Coverage & 3.75 & 0.88 & 1.36 & 0.65 & 0.46 & 1.00 \\
\hline
\end{tabular}


Table 9. Consolidated and Standardized Matrix.

\begin{tabular}{lcccccc}
\hline \multicolumn{1}{c}{ ATTRIBUTES } & Location & Effectiveness & Responsiveness & Speed & Price & Net Scope \\
\hline Location & 0.04 & 0.04 & 0.04 & 0.04 & 0.04 & 0.04 \\
Effectiveness & 0.17 & 0.17 & 0.17 & 0.17 & 0.17 & 0.17 \\
Responsiveness & 0.11 & 0.11 & 0.11 & 0.11 & 0.11 & 0.11 \\
Speed & 0.22 & 0.22 & 0.22 & 0.22 & 0.22 & 0.22 \\
Price & 0.32 & 0.32 & 0.32 & 0.32 & 0.32 & 0.32 \\
Coverage & 0.15 & 0.15 & 0.15 & 0.15 & 0.15 & 0.15 \\
\hline
\end{tabular}

insurance users give $r$ to each one of the attributes used in this study. Table 10 depicts the data.

When analyzing Table 10, it is possible to see that the most important attribute to health insurance users is "price" (31.77\%); and the least important is "location" (3.90\%). The speed in clearing payments and the effectiveness in solving problems also have some importance to consumers $(22.42 \%$ and $16.57 \%$, respectively). The consistency of these results, as all the others contained in this paper, can be easily verified.

Proceeding to the second phase of the work, we analyzed consumer preference of the companies, from the perspective of each one of the attributes already mentioned. The consolidated matrix of companies from the standpoint of the attribute "location" is presented in Table 11.

By standardizing the consolidated matrix of companies (Table 11), from the perspective of the attribute "location", we obtain Table 12.

From the standardized matrix, it is possible to determine the weights, in percentages, of each company, as seen in Table 13, concerning the attribute "location". These weights represent the importance that health care users give to each company, based on the attribute "location".

By observing Table 13, it is possible to conclude that the company with the greatest consumer preference, from the perspective of the attribute "location", is HP1 (with 35.82\%). On the other hand, the one which has the least preference is company HP6 (4.94\%). Company HP2 ranks second (24.71\%), while companies HP3 and HP4 have the same consumer preference (13.03\% and $11.02 \%$, respectively).

This analysis is an important consideration to better define the location and geographical distribution of user service points.

Working in the same way, the company weights and preference percentages are obtained in terms of the other attributes: effectiveness, responsiveness, speed, price and coverage, presented in Tables 14, 16, 17 and 18, respectively.

From Table 14, we can observe that the company which has the highest consumer preference, in terms of "effectiveness", is HP1 (with 30.30\%) and the least preferred is HP7 (4.80\%). On the other hand, company
Table 10. Weights and preference percentages of companies' attributes.

\begin{tabular}{lcc}
\hline \multicolumn{1}{c}{ ATTRIBUTES } & Weights & Percentages (\%) \\
\hline Location & 0.04 & 3.90 \\
Effectiveness & 0.17 & 16.57 \\
Responsiveness & 0.11 & 10.72 \\
Speed & 0.22 & 22.42 \\
Price & 0.32 & 31.77 \\
Coverage & 0.15 & 14.62 \\
\hline
\end{tabular}

HP2 ranks second in preference (26.11\%). This analysis is important for the choice of the accredited health care providers.

Table 15 shows that the company with the highest consumer preference, in terms of the attribute "responsiveness", is HP1 (34.73\%); HP2 ranks second in preference $(27.78 \%)$, while the other companies share the rest of consumers preference (between 4.73\% and $11.58 \%$ ). This analysis is important to better design the consumer service structure and processes.

Similarly, Table 16 shows that the company with highest consumer preference, in terms of the attribute "speed" is HP2 (32.74\%); the lowest in preference is HP7 (5.23\%). Company HP1 ranks second in preference (with $31.10 \%$ ). This analysis is important to better design the consumer service criteria and processes.

Table 17 shows that the companies with the highest consumer preference, in terms of the attribute "price", are companies HP6 and HP7 (25.41\%); the least preferred are companies HP1 and HP2 (3.51\% and $4.12 \%$, respectively). This analysis is important for the determination of the price of the accredited network.

As seen in Table 18, the company with the highest consumer preference in terms of the attribute "coverage" of the accredited network is HP1 (30.80\%); the lowest in preference are HP6 and HP7 (5.89\% and $5.98 \%$, respectively). This analysis is an important consideration for health insurance providers when determining their accredited network of physicians, clinics and hospitals.

Finally, after analyzing the preferences in terms of each attribute, we were able to determine the global consumer preference of companies, by calculating the weighted mean of consumer preference for 
Table 11. Consolidated Matrix of company preference considering the attribute "location".

\begin{tabular}{ccccccccc}
\hline COMPANIES & HP1 & HP2 & HP3 & HP4 & HP5 & HP6 & HP7 \\
\hline HP1 & 1.00 & 1.45 & 2.75 & 3.25 & 6.55 & 7.25 & 7.15 \\
HP2 & 0.69 & 1.00 & 1.90 & 2.24 & 4.52 & 5.00 & 4.93 \\
HP3 & 0.36 & 0.53 & 1.00 & 1.18 & 2.38 & 2.64 & 2.60 \\
HP4 & 0.31 & 0.45 & 0.85 & 1.00 & 2.02 & 2.23 & 2.20 \\
HP5 & 0.15 & 0.22 & 0.42 & 0.50 & 1.00 & 1.11 & 1.09 \\
HP6 & 0.14 & 0.20 & 0.38 & 0.45 & 0.90 & 1.00 & 0.99 \\
HP7 & 0.14 & 0.20 & 0.38 & 0.45 & 0.92 & 1.01 & 1.00 \\
\hline
\end{tabular}

Source: field interview.

Table 12. Consolidated and standardized matrix of company preference considering the attribute "location".

\begin{tabular}{ccccccccc}
\hline COMPANIES & HP1 & HP2 & HP3 & HP4 & HP5 & HP6 & HP7 \\
\hline HP1 & 0.36 & 0.36 & 0.36 & 0.36 & 0.36 & 0.36 \\
HP2 & 0.25 & 0.25 & 0.25 & 0.25 & 0.25 & 0.25 \\
HP3 & 0.13 & 0.13 & 0.13 & 0.13 & 0.13 & 0.13 \\
HP4 & 0.11 & 0.11 & 0.11 & 0.11 & 0.11 & 0.11 \\
HP5 & 0.05 & 0.05 & 0.05 & 0.05 & 0.05 & 0.05 \\
HP6 & 0.05 & 0.05 & 0.05 & 0.05 & 0.05 & 0.05 \\
HP7 & 0.05 & 0.05 & 0.05 & 0.05 & 0.05 & 0.05 \\
\hline
\end{tabular}

Table 13. Company preference weights and percentages of in terms of the attribute "location".

\begin{tabular}{ccc}
\hline COMPANY & Weights & Percentages $(\%)$ \\
\hline HP1 & 0.36 & 35.82 \\
HP2 & 0.25 & 24.71 \\
HP3 & 0.13 & 13.03 \\
HP4 & 0.11 & 11.02 \\
HP5 & 0.05 & 5.47 \\
HP6 & 0.05 & 4.94 \\
HP7 & 0.05 & 5.01 \\
\hline
\end{tabular}

Table 14. Company preference weights and percentages in terms of the attribute "effectiveness".

\begin{tabular}{ccc}
\hline COMPANY & Weights & Percentages $(\%)$ \\
\hline HP1 & 0.30 & 30.30 \\
HP2 & 0.26 & 26.11 \\
HP3 & 0.14 & 13.97 \\
HP4 & 0.11 & 10.92 \\
HP5 & 0.08 & 8.46 \\
HP6 & 0.06 & 5.72 \\
HP7 & 0.05 & 4.80 \\
\hline
\end{tabular}

each company with the preference weights of each attribute. Thus, we obtained Table 19.

Observing the values in Table 19, it is possible to identify two sets of companies. Companies HP1 and HP2 are preferred by $23.56 \%$ and $19.11 \%$, respectively, of health insurance users, totaling about $43 \%$ of the preference. The other companies received about 10\% preference each, totaling about 57\%.
Table 15. Company preference weights and percentages in terms of the attribute "responsiveness".

\begin{tabular}{ccc}
\hline COMPANY & Weights & Percentage (\%) \\
\hline HP1 & 0.35 & 34.73 \\
HP2 & 0.28 & 27.78 \\
HP3 & 0.12 & 11.58 \\
HP4 & 0.10 & 10.07 \\
HP5 & 0.06 & 6.26 \\
HP6 & 0.05 & 4.86 \\
HP7 & 0.05 & 4.73 \\
\hline
\end{tabular}

Table 16. Company preference weights and percentages in terms of the attribute "speed".

\begin{tabular}{ccc}
\hline COMPANY & Weights & Percentage $(\%)$ \\
\hline HP1 & 0.31 & 31.10 \\
HP2 & 0.32 & 32.74 \\
HP3 & 0.10 & 9.87 \\
HP4 & 0.08 & 8.29 \\
HP5 & 0.07 & 6.84 \\
HP6 & 0.06 & 5.92 \\
HP7 & 0.05 & 5.23 \\
\hline
\end{tabular}

By analyzing all the Tables (10 through 19) combined, one may conclude that some companies with lower rank in the "operational attributes" compensate their deficiencies with the "price attribute". Or, from another viewpoint, in order to offer lower prices they opt for reducing the "quality" of their services. This is an indication that companies focus on specific target audiences. 
Table 17. Company preference weights and percentages in terms of the attribute "price".

\begin{tabular}{ccc}
\hline COMPANY & Weights & Percentage $(\%)$ \\
\hline HP1 & 0.04 & 3.51 \\
HP2 & 0.04 & 4.12 \\
HP3 & 0.13 & 13.15 \\
HP4 & 0.12 & 12.44 \\
HP5 & 0.16 & 15.95 \\
HP6 & 0.25 & 25.41 \\
HP7 & 0.25 & 25.41 \\
\hline
\end{tabular}

Tabela 18. Company preference weights and percentages in terms of the attribute "coverage".

\begin{tabular}{ccc}
\hline COMPANY & Weights & Percentage (\%) \\
\hline HP1 & 0.37 & 36.80 \\
HP2 & 0.15 & 15.02 \\
HP3 & 0.21 & 21.03 \\
HP4 & 0.09 & 8.66 \\
HP5 & 0.07 & 6.63 \\
HP6 & 0.06 & 5.89 \\
HP7 & 0.06 & 5.98 \\
\hline
\end{tabular}

Table 19. Gobal preference weights and percentages for the companies.

\begin{tabular}{ccc}
\hline COMPANY & Weights & Percentage (\%) \\
\hline HP1 & 0.24 & 23.56 \\
HP2 & 0.19 & 19.11 \\
HP3 & 0.14 & 13.53 \\
HP4 & 0.10 & 10.40 \\
HP5 & 0.10 & 9.86 \\
HP6 & 0.12 & 11.93 \\
HP7 & 0.12 & 11.62 \\
\hline
\end{tabular}

\section{Conclusions}

This work shows how to use $A H P$ to study the image of health insurance companies. This technique allows us to assess how customers see the companies analyzed from different aspects (attributes considered by users as important in the provision of services).

One criterion used for this study to ensure the consistency of judgment matrices (without making the adjustments recommended by the AHP technique), concerns the judgment by pairs. Instead of trying all possible combinations, this study focuses on judging a single criterion (base criterion) in relation to all others, as recommended by Silva (2007). Relationships among the other combinations are calculated mathematically, according to the proportion relationships determined of criterion-based judgment. In addition to ensuring the consistency of the judgment matrix, this reduces the number of issues related to the judgment, thus minimizing the time spent with interviewees.
Companies may redesign their structures, their processes, their prices and their accredited networks on the basis of the results obtained by analyzing each attribute. User preference is clear and well-defined. We may see that, though price is the most important attribute, the company preferred by users is the one with the other most desirable attributes (related to the quality of services).

Considering the overall result, companies may decide whether they should continue focusing on their specific target audiences or whether they wish to expand their markets.

For the future, a study focusing on the different target audiences may refine the work presented here.

\section{References}

AAKER, D. Criando e administrando marcas de sucesso. São Paulo: Futura, 1996. PMid:8877580.

ACZÉL, J.; SAATY, T. L. Procedures for synthesyzyng ratio judgements. Journal of Mathematical Psychology, v. 27, p. 93-102, 1983. http://dx.doi.org/10.1016/00222496(83)90028-7

BELTON, V. A.; GEAR, T. The legitimacy of rank reversal - a comment. Omega, v. 13, p. 143-144, 1985. http://dx.doi. org/10.1016/0305-0483(85)90052-0

BHUSHAN, N.; RAl, K. Strategic Decision Making: Applying the Analytic Hierarchy Process. New York: Springer, 2004.

BLANCO, M. C. Aplicación del analitic process em la medida de la imagen de marca de servicios. 1996. Tese (Doutorado)Universidad de Leon, Leon, 1996.

BOND, S. D.; CARLSON, K. A.; KEENEY, R. L. Generating Objectives: Can Decision Makers Articulate What They Want? Management Science, v. 54, n. 1, p. 56-70, 2008. http://dx.doi.org/10.1287/mnsc. 1070.0754

BRANCO, G. M.; RIBEIRO, J. L. D.; TINOCO, M. A. C. Determinantes da satisfação e atributos da qualidade em serviços de hotelaria. Produção, v. 20, n. 4, p. 576-588, 2010. http://dx.doi.org/10.1590/S010365132010005000057

BRANS, J. P.; MARESHAL, B.; VINCKE, P. Prométhée: a new family of outranking methods in multicriteria analysis, in Operational Research. Amsterdam; London; New York: North-Holland, 1984. p. 408-421.

COSTA, H. G.; MOLL, R. N. Emprego do método de análise hierárquica (AHP) na seleção de variedades para 0 plantio de cana de açúcar. Gestão e Produção, v. 6, n. 3, p. 243-256, 1999. http://dx.doi.org/10.1590/S0104530X1999000300009

COSTA, H. G. et al. ELECTRE TRI aplicado a avaliação da satisfação de consumidores. Revista Produção, v. 17, n. 2, p. 230-245, 2007. http://dx.doi.org/10.1590/ S0103-65132007000200002

CRUZ JUNIOR, A. T.; CARVALHO, M. M. Obtenção da voz do consumidor: estudo de caso em um hotel ecológico. Revista Produção, v. 13, n. 3, p. 88-100, 2003. http:// dx.doi.org/10.1590/S0103-65132003000300008

GUSTAFSSON, A.; JOHNSON, M. Bridging the qualitysatisfaction gap. Quality Management Journal, v. 4, n. 3, p. 27-43, 1997. 
HWANG, C. L.; YOON, K. Multiple Attribute Decision Making: Methods and Applications - A State-of-theArt Survey. Berlin: Springer-Verlag, 1981. http://dx.doi. org/10.1007/978-3-642-48318-9

ISHIZAKA, A. Clusters and pivots for evaluating a large number of alternatives in AHP. Pesquisa Operacional, v. 32, n. 1, p. 87-101, 2012. http://dx.doi.org/10.1590/ S0101-74382012005000002

LIBERATORE, M. J.; NYDICK, R. L. The analytic hierarchy process in medical and health care decision making: A literature review. European Journal of Operational Research, v. 189, p. 194-207, 2008. http://dx.doi. org/10.1016/j.ejor.2007.05.001

LOOTSMA, F. A. A multiplicative variant of the analytic hierarchy process. Delft: Delft University of Technology, 1990. Report of the faculty of technical mathematics and informatics, n. 90-45.

MIRANDA, C. M. G.; ALMEIDA, A. T. Avaliação de pósgraduação com método ELECTRE TRI - o caso de engenharias 111 da capes. Revista Produção, v. 13, n. 3, p. 101-112, 2003. http://dx.doi.org/10.1590/S010365132003000300009

MUNHOZ, D. C. G.; CASTILHO, M. Design of a methodology for identifying e selecting the best alternative in acquiring the information system for company. Proceedings of the International Symposium on the Analytic Hierarchy Process, 2009.

PARASURAMAN, M.; BERRY, L.; ZEITHAML, V. Delivering Quality Service. New York: The Free Press, 1990.

ROY, B. Classement et choix em présence de points de vue multiples. La méthode Electre, v. 8, p. 57-75, 1986.

SAATY, T. L. The Analytic Hierarchy Process. New York: McGraw-Hill International, 1980.
SAATY, T. L. Theory and Applications of the Analytic Network Process: Decision Making with Benefits, Opportunities, Costs, and Risks. Pittsburgh: RWS Publications, 2005.

SILVA, D. M. R. Aplicação do Método AHP para Avaliação de Projetos Industriais. 2007. Dissertação (Mestrado)Pontifícia Universidade Católica do Rio de Janeiro, Rio de Janeiro, 2007.

STEINER, P. A.; BRAGA, M. C. B.; STEINER, M. T. A. Hierarchy of Shopping Centers in the City of Curitiba, State of Paraná, Brazil. International Journal of Computer Science and Network Security, v. 10, n. 5, p. 198-207, 2010.

SZAJUBOK, N. K.; MOTA, C. M. M.; ALMEIDA, A. T. Uso do método multicritério ELECTRE TR1 para classificação de estoques na construção civil. Revista Pesquisa Operacional, v. 26, n. 3, p. 625-648, 2006.

TRIANTAPHYLLOU, E.; MANN, S. H. Using the Analytic Hierarchy Process For Decision Making in Engineering Applications: Some Challenges. International Journal of Industrial Engineering: Applications and Practice, v. 2, n. 1, p. 35-44, 1995.

VAIDYAA, O. S.; KUMARB, S. Analytic hierarchy process: an overwiew of applications. European Journal of Operational Research, v. 169, n. 1, p. 1-29, 2006. http:// dx.doi.org/10.1016/j.ejor.2004.04.028

VALOIS, U.; ALMEIDA, A. T. Modelo de apoio à decisão multicritério para terceirização de atividades produtivas baseado no Método smarts. Produção, v. 19, n. 2, p. 249-260, 2009. http://dx.doi.org/10.1590/S010365132009000200003

WATSON, S. R.; FREELING, A. N. S. Assessing attribute weigths by ratios. Omega, v. 10, p. 582-583, 1982. http://dx.doi.org/10.1016/0305-0483(82)90061-5 